\title{
Chronic cannabinoid administration in vivo compromises extinction of fear memory
}

\author{
Hui-Ching Lin, Sheng-Chun Mao, Po-See Chen, and Po-Wu Gean ${ }^{1}$
}

Institute of Basic Medical Sciences and Department of Pharmacology, Center for Gene Regulation and Signal Transduction Research, National Cheng-Kung University, Tainan, Taiwan 701

\begin{abstract}
Endocannabinoids are critically involved in the extinction of fear memory. Here we examined the effects of repeated cannabinoid administration on the extinction of fear memory in rats and on inhibitory synaptic transmission in medial prefrontal cortex (mPFC) slices. Rats were treated with the CB1 receptor agonist WIN55212-2 (WIN $10 \mathrm{mg} / \mathrm{kg}$, i.p.) once per day for $7 \mathrm{~d}$. On day 8 , the rats were submitted to a standard fear conditioning procedure, and retention of memory was measured with potentiated startle paradigm. We found that (1) WIN-pretreated rats exhibited much less extinction to cue alone presentations; (2) the reduction of fear-potentiated startle normally seen when the CBI receptor agonists were infused into the mPFC was absent in the WIN-pretreated rats; (3) WIN-induced inhibition of GABAergic transmission was significantly less in slices from the WIN-pretreated rats than that from the vehicle-pretreated control; (4) WIN failed to induce extracellular signal-regulated kinases (ERKs) phosphorylation in the WIN-pretreated rats; and (5) the level of CBI receptor in the WIN-pretreated rats was lower than that of vehicle-pretreated rats. These results suggest that endocannabinoids within the mPFC play an important role in the extinction of conditioned fear. However, long-term marijuana use may limit its clinical efficacy for the treatment of anxiety disorders.
\end{abstract}

Post-traumatic stress disorder (PTSD) is an incapacitating chronic syndrome that involves a cognitive, emotional, and physiological failure to adequately process and/or recover from experience with a life-threatening condition such as a natural disaster, violent personal assault, war, or severe automobile accident. Pavlovian fear conditioning in rats in which a cue (conditioned stimulus, CS) comes to induce fear when it has been repeatedly paired with a noxious stimulus (unconditioned stimulus, US) is a commonly used animal model of traumatic fear (Davis 2000; LeDoux 2000). One of the advantages of this model is that the conditioned response can be bi-directionally manipulated. The acquired responses will gradually decrease if the animal is exposed only to the CS without pairing with the US, a phenomenon referred to as "extinction" (Pavlov 1927; Falls et al. 1992; Rescorla 2001). It is thought that extinction represents an active learning that forms inhibitory association between the CS and the US resulting in suppression of the original association (Berman and Dudai 2001; Bouton 2002; Myers and Davis 2002). It has been shown that the medial prefrontal cortex (mPFC) plays an important role in the extinction of conditioned fear (Maren and Quirk 2004; SotresBayon et al. 2004; Quirk et al. 2006). During extinction training, mPFC neurons activate and cause sufficient depolarization of intercalated neurons to produce relatively more inhibition on the central nucleus of the amygdala (CeA) leading to the suppression of conditioned fear (Royer and Pare 2002; Quirk et al. 2003; Likhtik et al. 2005). Alternatively, mPFC projection neurons activate BLA inhibitory interneurons leading to feedforward inhibition of BLA principal neurons (Rosenkranz and Grace 2001).

Cannabinoids, the active components of Cannabis sativa and their derivatives, have a wide spectrum of pharmacological effects exerted through cannabinoid type 1 (CB1) receptors. In humans, cannabis can promote relaxing effects via relieving anxious states or panic attacks (Iversen 2003). In animal experiments, microinfusion of the cannabinoid agonist $\Delta^{9}$ -

\footnotetext{
${ }^{1}$ Corresponding author.
}

E-mail powu@mail.ncku.edu.tw; fax (886)-6-2749296.

Article is online at http://www.learnmem.org/cgi/doi/10.1101/lm.1081908. tetrahydrocannabinol (THC) at low doses into the prefrontal cortex induces an anxiolytic-like response tested with elevated plusmaze (Rubino et al. 2008). The anxiolytic effect of THC in the prefrontal cortex was paralleled by an increase in cAMP response element-binding protein (CREB) phosphorylation, suggesting that the prefrontal cortex is an important brain area for cannabinoids to modulate emotional state. On the other hand, cannabinoids could produce anxiety that likely depended on the doses used, with higher doses eliciting anxiogenic-like responses (Tournier et al. 2003; Viveros et al. 2005). The bi-directional effects could also lie in the previous history of the individual and environmental context (Viveros et al. 2005). An elegant study by Marsicano et al. (2002) indicates that endocannabinoids are critically involved in the extinction of fear memory. Mutant mice lacking CB1 receptors were specifically impaired in the extinction of conditioned fear (Marsicano et al. 2002). In parallel, CB1 receptor antagonists prevented extinction in the wild-type animals. In addition, enhancement of extinction was noted in rats treated with a cannabinoid reuptake inhibitor (Chhatwal et al. 2005). These results suggest that activation of the CB1 receptor by endocannabinoids is essential for the extinction and open a new avenue for the treatment of anxiety disorders (Barad et al. 2006). The purpose of this study was to examine the effects of repeated cannabinoid administration on the extinction of fear memory in rats. Such a study is important because of the widespread and often long-term use of marijuana by humans for medical and illicit purposes. Especially, behavioral and biochemical studies in animals have demonstrated the rapid development of tolerance to many of the effects of cannabinoid during chronic administration (Maldonado 2002; Martin et al. 2004).

\section{Results}

Development of tolerance to antinociceptive effect of WIN after chronic treatment

The first experiment aimed to test the development of tolerance by comparing the efficacy of WIN's antinociceptive effect after 
chronic WIN treatment (hereafter referred to as "WIN pretreatment"). Rats were injected with WIN (10 mg/kg, i.p.) or vehicle once per day for $7 \mathrm{~d}$. On day 8 , all rats were injected with WIN (10 $\mathrm{mg} / \mathrm{kg}$, i.p.), and $20 \mathrm{~min}$ later, antinociceptive effect was assessed using the tail-flick test. In the 1-d withdrawal group, a two-way ANOVA revealed a significant effect of group (vehicle- vs. WINpretreatment, $F_{(1,20)}=14.45, P<0.001$ ), drug treatment (WIN vs. vehicle, $\left.F_{(1,20)}=61.35, P<0.001\right)$, and a significant interaction $\left(F_{(1,20)}=13.62, P<0.001\right)$. Reaction time in the WIN pretreatment-WIN rats was significantly shorter than that in the vehicle pretreatment-WIN rats $(P<0.001)$. Furthermore, baseline latency in the vehicle pretreatment-WIN rats was comparable with that of WIN pretreatment-WIN rats $(P>0.5)$, indicating that the reduced latency was not due to the residual effect of WIN.

We next determined the time course of recovery from tolerance to antinociceptive effect. After WIN pretreatment, rats were randomly assigned to 7- or 14-d groups according to the time between the last injection and the assessment of antinociceptive effect. Thus, in the 7-d group, the rats were given WIN (10 $\mathrm{mg} / \mathrm{kg}$, i.p.) $7 \mathrm{~d}$ after the last injection (on day 15), and the antinociceptive effect of WIN was assessed $20 \mathrm{~min}$ later. As shown in Figure 1, significantly less antinociceptic effect was observed in 1-d and 7-d groups. Importantly, there was no difference in the tail-flick responses of the 14-d group between the vehicle-pretreated and the WIN-pretreated rats, indicating a complete reversal of tolerance following $14 \mathrm{~d}$ of withdrawal.

\section{Agonist-induced loss of $\mathrm{CB} 1$ receptor}

\section{in synaptoneurosome preparation of the IL}

Previous reports suggest that the CB1 receptor, like many Gprotein-coupled receptors, underwent agonist-induced endocytosis (Hsieh et al. 1999; Coutts et al. 2001). To determine whether the tolerance to antinociception after WIN pretreatment was associated with receptor internalization, we measured CB1 receptors using synaptoneurosome preparation. Rats were treated chronically with WIN as described above. On day 8, the synaptoneurosomes of the IL were prepared, and CB1 receptor was quantified by Western blot analysis. As illustrated in Figure 2, there was no difference in the amount of CB1 receptor between naive and vehicle-pretreated rats. In contrast, the levels of CB1 receptor of the WIN-pretreated rats were significantly lower than

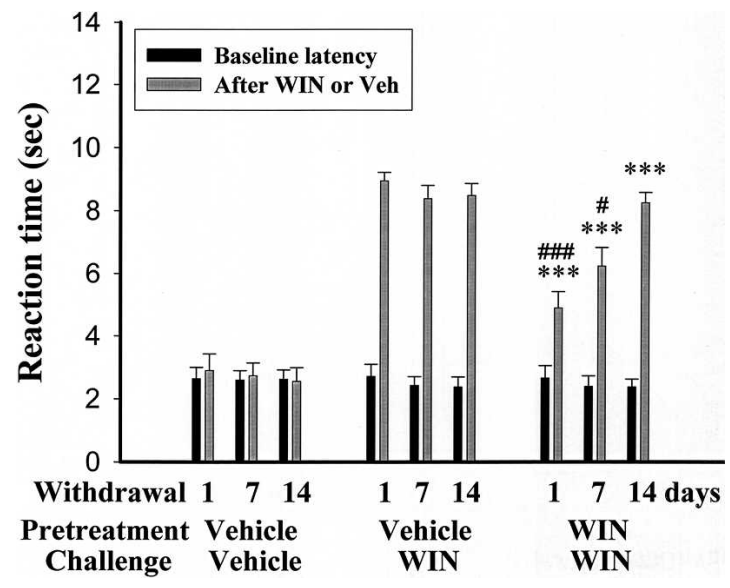

Figure 1. Tolerance to antinociception after WIN pretreatment. Rats were injected with WIN $(10 \mathrm{mg} / \mathrm{kg}$, i.p.) or vehicle once per day for $7 \mathrm{~d}$. On day 8 (withdrawal $1 \mathrm{~d}, n=6$ ), 15 (withdrawal $7 \mathrm{~d}, n=6$ ), or 22 (withdrawal $14 \mathrm{~d}, n=6)$, all rats were injected with WIN (10 mg/kg, i.p.), and 20 min later antinociceptive effect was assessed using the tail-flick test. $\left({ }^{* *}\right) P<0.001$ vs. baseline latency; (\#) $P<0.05$; (\#\#\#) $P<0.001$ vs. vehicle pretreatment.

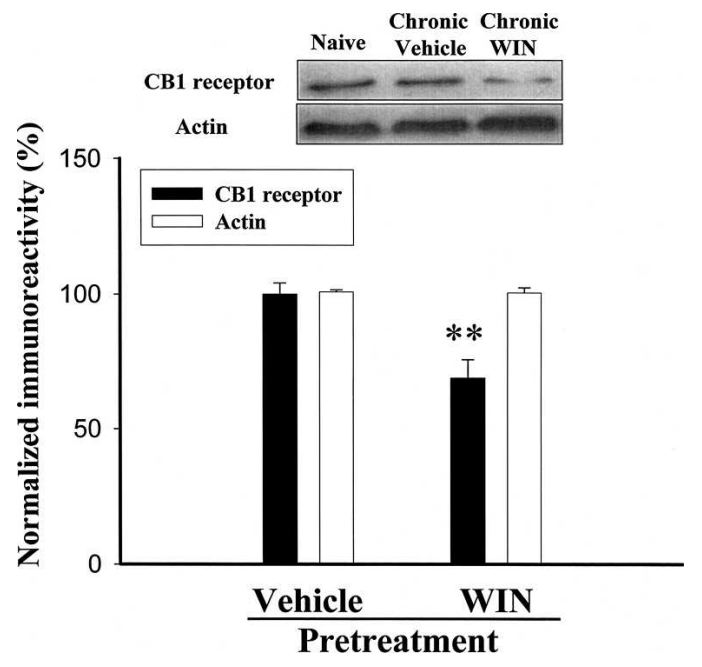

Figure 2. Decrease in the expression of $C B 1$ receptors after WIN pretreatment. Rats were injected with WIN $(10 \mathrm{mg} / \mathrm{kg}$, i.p., $n=4)$ or vehicle $(n=4)$ once per day for $7 \mathrm{~d}$. On day 8 , the tissue of IL was dissected out, and synaptoneurosomes were prepared. Expression of CB1 receptor was determined by quantitative immunoblotting. $\left({ }^{* *}\right) P<0.01$ vs. vehicle pretreatment.

that of naïve and vehicle rats $(68.7 \% \pm 6.8 \%$ of naïve, $P<0.01$ vs. vehicle).

\section{Tolerance to WIN-induced ERKs phosphorylation in the $\mathrm{mPFC}$}

Rats were injected intraperitoneally with WIN or vehicle daily for $7 \mathrm{~d}$ and killed on the eighth day; IL slices were made. Slices were incubated with WIN $(2 \mu \mathrm{M})$ for $15 \mathrm{~min}$, and ERK phosphorylation was analyzed with antibody directly against the active form of ERKs. As shown in Figure 3, application of WIN significantly increased the phosphorylated levels of ERK44 $(156.8 \% \pm 16.4 \%$, $n=6, P<0.01)$ and ERK42 $(131.5 \% \pm 11.6 \%, n=6, P<0.05)$ in slices from the vehicle-pretreated rats. When mitogen-activated protein kinase (MAPK) kinase (MEK) inhibitor U0126 (10 $\mu \mathrm{M})$

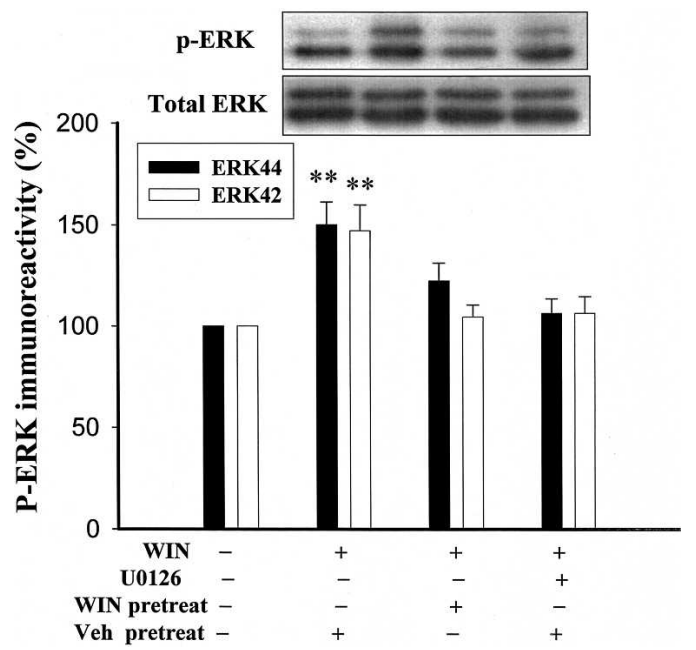

Figure 3. Tolerance to WIN-induced phosphorylation of ERKs in the $\mathrm{mPFC}$ slices. Rats were pretreated with WIN $(10 \mathrm{mg} / \mathrm{kg}$, i.p., $n=6)$ or vehicle $(n=6)$ once per day for $7 \mathrm{~d}$, and mPFC slices were made the next day. Slices were incubated with WIN $(2 \mu \mathrm{M})$ for $15 \mathrm{~min}$, and then WIN was washed out. ERK phosphorylation was analyzed with antibody directly against the active form of ERKs. $\left.{ }^{* *}\right) P<0.01$ vs. Chronic vehicle. 
was present, ERK phosphorylation induced by WIN was abolished (ERK44: 99.2\% \pm 15.3\%; ERK42: 94.0\% $\pm 10.2 \%, n=6$ ). Equal loading was confirmed when cellular extract was blotted with antibody that recognized ERKs independently of their phosphorylation state. In contrast, there was considerably less increase in the phosphorylated levels of ERK44 $(122.5 \% \pm 8.8 \%$, $n=6, P<0.01)$ and ERK42 $(104.5 \% \pm 5.9 \%, n=6, P<0.01)$ induced by WIN in slices from the WIN-pretreated rats.

\section{Resistance to extinction training-induced reduction of fear-potentiated startle after WIN pretreatment}

We next determined whether WIN-pretreated rats exhibited superior or less extinction. Rats were pretreated with WIN as in the above experiments. On day 8 , the rats were subjected to a standard fear conditioning procedure, and fear-potentiated startle was measured $24 \mathrm{~h}$ later (Test 1 , on day 9). On day 10 , the rats received 30 extinction trials in which the light was presented alone, and fear-potentiated startle was measured $24 \mathrm{~h}$ after extinction training (Test 2). Two-way ANOVA revealed that there was no significant effect of group (vehicle vs. WIN pretreatment, $\left.F_{(1,20)}=3.35, P=0.082\right)$, but a significant effect of drug treatment (WIN vs. vehicle, $F_{(1,20)}=4.60, P<0.05$ ) and interaction $\left(F_{(1,20)}=4.67, P<0.05\right)$. The difference between light-noise and noise alone in the WIN pretreatment-WIN rats was significantly higher than that in the vehicle pretreatment-WIN rats $(P<0.05)$ (Fig. 4A). Furthermore, baseline startle in the vehicle pretreatment-WIN rats was comparable with that of WIN pretreatmentWIN rats $(P=0.83)$. It was noted that the difference between light-noise and noise alone before extinction training in the vehicle pretreatment rats was comparable with that of WIN pretreatment rats $(P=0.85)$, indicating that WIN pretreatment did not affect the consolidation of fear memory.

Since the antinociceptive effect of WIN recovered in $14 \mathrm{~d}$ after withdrawal of WIN, we examined whether resistance to extinction reversed at the same time course. Rats were pretreated with WIN as described previously and $14 \mathrm{~d}$ later (day 22) were given 10 light-foot shock pairings, and fear-potentiated startle was measured $24 \mathrm{~h}$ later. On day 24 , the rats received extinction training (three blocks of 10 presentations of light-alone trials). After $14 \mathrm{~d}$ of WIN withdrawal, the rats exhibited significant extinction. Startle potentiation in these rats were $198.1 \% \pm 25.9 \%$ before and $57.0 \% \pm 14.4 \%(n=5, P<0.01)$ after the extinction training (Fig. 4B).

\section{Resistance to facilitation of extinction after chronic WIN treatment}

We have previously shown that infusion of a low dose of WIN $(0.05 \mu \mathrm{g})$ into the IL facilitated extinction of fear memory. We determined whether this facilitating effect was altered after WIN pretreatment. The WIN-pretreated rats were conditioned, and memory retention was assessed $24 \mathrm{~h}$ later (Test 1 ). On the next day, the rats received $10 \mathrm{CS}$-alone trials, and memory retention was assessed $24 \mathrm{~h}$ later (Test 2). WIN $(0.05 \mu \mathrm{g})$ was infused into the IL $30 \mathrm{~min}$ before CS-alone trials. Figure 5 shows that startle potentiation in these rats were $206.9 \% \pm 29.9 \%$ before and $181.3 \% \pm 29.5 \%$ after extinction training $\left(t_{(6)}=0.56, P=0.60\right)$, indicating that the facilitating effect of WIN was markedly reduced after WIN pretreatment. (Fig. 5).

\section{Resistance to WIN-induced reduction} of fear-potentiated startle after WIN pretreatment

We next determined whether WIN pretreatment altered the sensitivity of fear-potentiated startle to WIN-mediated inhibition. The WIN-pretreated rats were conditioned, and memory retention was assessed $24 \mathrm{~h}$ later (Test 1 ). On the next day, the rats
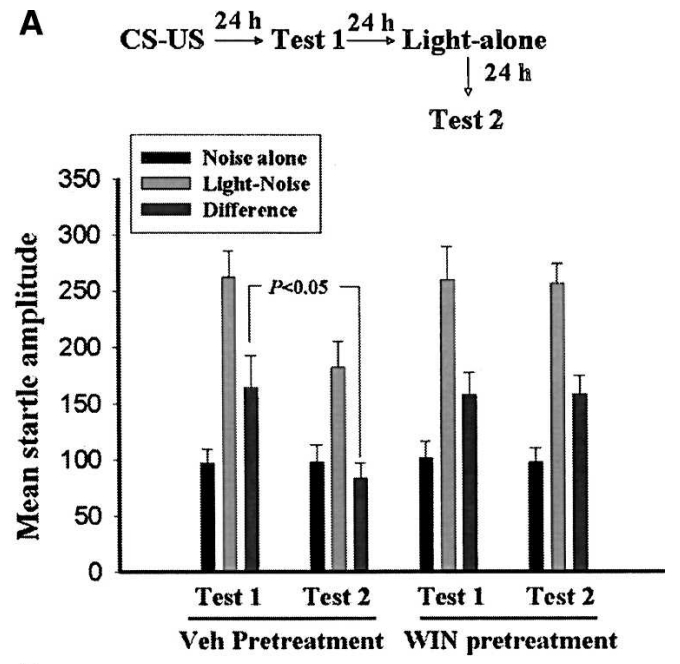

B

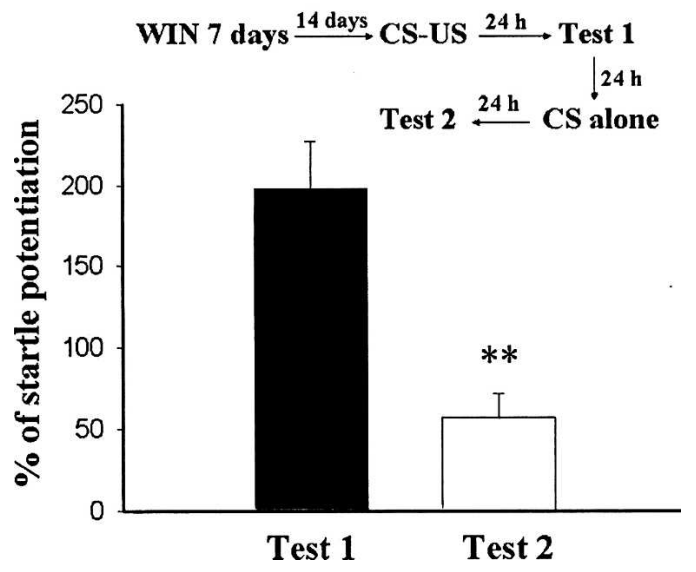

Figure 4. Tolerance to extinction of conditioned fear after WIN pretreatment. $(A)$ Rats were injected with WIN $(10 \mathrm{mg} / \mathrm{kg}$, i.p., $n=6)$ or vehicle $(n=6)$ once per day for $7 \mathrm{~d}$. On day 8 , all rats were given 10 light-foot shock pairings, and retention of memory was tested $24 \mathrm{~h}$ later (Test 1). On day 10 , the rats received extinction training (three blocks of 10 presentations of light-alone trials), and the percentage of fearpotentiated startle was measured $24 \mathrm{~h}$ after extinction training (Test 2). $\left.{ }^{*}\right) P<0.05$ vs. Test 1 . (B) Recovery of extinction after withdrawal of WIN. Rats $(n=5)$ were pretreated with WIN as described in A. On day 22 (withdrawal $14 \mathrm{~d}$ ), the rats were given 10 light-foot shock pairings, and retention of memory was tested $24 \mathrm{~h}$ later (Test 1 ). On day 24 , the rats received extinction training (three blocks of 10 presentations of lightalone trials), and the percentage of fear-potentiated startle was measured $24 \mathrm{~h}$ after extinction training (Test 2 ). $\left(^{* *}\right) P<0.01$ vs. Test 1.

received intra-IL infusion of WIN $(1 \mu \mathrm{g})$, and the percentage of fear-potentiated startle was measured $24 \mathrm{~h}$ later (Test 2 ). The vehicle-pretreated rats exhibited significantly reduced startle after WIN infusion to the IL. Startle potentiation in these rats was $173.5 \% \pm 16.6 \%$ before and $87.5 \% \pm 12.7 \%$ after WIN infusion $(n=6, P<0.01)$. In contrast, infusion of WIN to the IL did not influence the startle potentiation in the WIN-pretreated rats $(n=6, P=0.74)$ (Fig. 6A), demonstrating less sensitivity to WIN in these rats. Furthermore, Test 1 of the WIN-pretreated rats was comparable with Test 1 of the vehicle-pretreated rats, ruling out a nonspecific effect of residual WIN on the fear-potentiated startle. The infusion cannula tip locations are shown in the Figure $6 \mathrm{~B}$.

Rats were pretreated with WIN for $7 \mathrm{~d}$, and $14 \mathrm{~d}$ after the last injection (day 22) were given 10 light-foot shock pairings. Fear- 


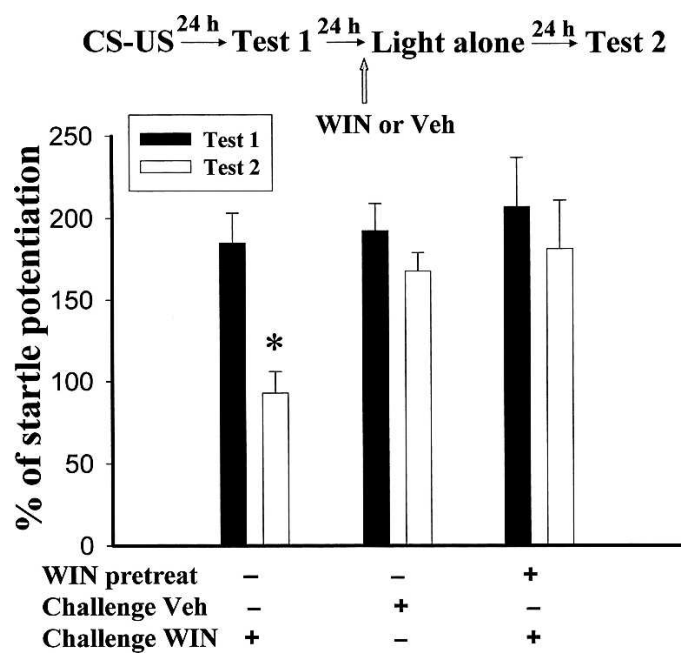

Figure 5. Tolerance to WIN-induced facilitation of extinction after WIN pretreatment. Rats were injected with WIN $(10 \mathrm{mg} / \mathrm{kg}$, i.p., $n=7)$ or vehicle $(n=12)$ once per day for $7 \mathrm{~d}$. On day 8 , the rats were given 10 light-foot shock pairings and retention of memory was tested $24 \mathrm{~h}$ later (Test 1 ). On day 10 , the rats received 10 CS-alone trials, and memory retention was assessed $24 \mathrm{~h}$ later (Test 2$)$. WIN $(0.05 \mu \mathrm{g})$ was infused into the IL 30 min before CS-alone trials in seven WIN-pretreated and six vehicle-pretreated rats. In another six vehicle-pretreated rats, vehicle was infused into the IL 30 min before CS-alone trials. $\left(^{*}\right) P<0.05$ vs. Test 1 .

potentiated startle was measured $24 \mathrm{~h}$ later (Test 1$)$. On day 24 , the rats received intra-IL infusion of WIN $(1 \mu \mathrm{g})$, and the percentage of fear-potentiated startle was measured $24 \mathrm{~h}$ later (Test 2). Figure $6 \mathrm{C}$ shows that the rats exhibited significant extinction after $14 \mathrm{~d}$ of WIN withdrawal. Startle potentiations in these rats were $202.9 \% \pm 30.5 \%$ before and $91.4 \% \pm 25.5 \% \quad(n=5$, $P<0.05)$ after the extinction training.

\section{Tolerance to WIN-induced inhibition of GABAergic neurotransmission in the mPFC}

Inhibition of GABAergic transmission in the hippocampus resulted in neuronal synchronization (Chagnac-Amitai and Connors 1989) and facilitated induction of long-term potentiation (LTP) of excitatory transmission (Carlson et al. 2002; Chevaleyre and Castillo 2003). If inhibition of GABAergic transmission in the mPFC led to inhibition of amygdala-mediated expression of conditioned fear and contributed to WIN-induced extinction, then WIN-pretreated rats might exhibit decreased sensitivity to WIN inhibition of GABAergic transmission. To test this possibility, whole-cell patch clamp recordings were made from $\mathrm{mPFC}$ slices prepared from WIN- or vehicle-pretreated rats. In five neurons tested, the input resistance $\left(R_{\mathrm{in}}\right)$ of IL neurons from vehiclepretreated rats was $298.9 \pm 23.7 \mathrm{M} \Omega(n=5)$, which was not different from that of vehicle-pretreated rats $(295.0 \pm 18.2 \mathrm{M} \Omega$, $n=5, P>0.1)$. Orthodromic stimuli applied to the layer II of rat prefrontal cortex slices elicited excitatory postsynaptic currents (EPSCs) in layer V (Huang et al. 2004). Bath application of the AMPA receptor antagonist CNQX $(10 \mu \mathrm{M})$ plus the NMDA receptor antagonist D-APV $(50 \mu \mathrm{M})$ blocked the EPSCs, revealing an IPSC that was completely blocked by bicuculline $(10 \mu \mathrm{M})$, confirming the mediation by $\mathrm{GABA}_{\mathrm{A}}$ receptors (Fig. 7A). Figure $7 \mathrm{~B}$ shows that no difference was observed between vehicle- and WIN-pretreated rats in the number of action potentials that could be elicited in response to 200-pA depolarizing current pulses. Application of different concentrations of WIN $(0.02,0.5$, and $2 \mu \mathrm{M}$ ) for $15 \mathrm{~min}$ significantly reduced the amplitude of IPSC in slices from the vehicle-pretreated $\left(F_{(2,12)}=37.2, P<0.001\right.$,

$n=5$ in each concentration) and WIN-pretreated $\left(F_{(2,12)}=10.7\right.$, $P<0.01, n=5$ in each concentration) rats in a concentrationdependent manner (Fig. 7C). The depressant effect of WIN on the IPSC was markedly reduced in slices from the WIN-pretreated rats (Fig. 7D). As can be seen from Figure 7E, the concentration of WIN that inhibited $20 \%$ of IPSC amplitude $\left(\mathrm{IC}_{20}\right)$ shifted approximately from $0.3 \mu \mathrm{M}$ to $1.9 \mu \mathrm{M}$ after chronic WIN treatment. It was noted that WIN $(2 \mu \mathrm{M})$ did not significantly affect $R_{\text {in }}$ in both vehicle-pretreated $\left(R_{\text {in }}\right.$ was $298.9 \pm 23.7 \mathrm{M} \Omega$ before and $291.5 \pm 22.8 \mathrm{M} \Omega$ after WIN) and WIN-pretreated $\left(R_{\text {in }}\right.$ was $295.0 \pm 18.2 \mathrm{M} \Omega$ before and $303.7 \pm 27.1 \mathrm{M} \Omega$ after WIN) rats.

The above experiments suggested that the startle-reducing effect of WIN was mediated by an inhibition of GABA release in the IL and that this effect was attenuated after WIN pretreatment. If this is the case, then application of $\mathrm{GABA}_{\mathrm{A}}$ receptor antagonist bicuculline to the IL should reduce startle potentiation irrespective of the rats that were pretreated with WIN or vehicle. Figure 8 shows that vehicle-pretreated rats exhibited significant reduction of startle potentiation after given bicuculline $(0.25 \mu \mathrm{g})$ to the IL. Startle potentiations in these rats were $173.5 \% \pm 16.6 \%$ before and $87.5 \% \pm 6.7 \%$ after administration of bicuculline $(P<0.05)$. Infusion of bicuculline $(0.25 \mu \mathrm{g} / \mathrm{side})$ to the IL similarly reduced fear-potentiated startle in the WIN-pretreated rats. Startle potentiations in these rats were $211.8 \% \pm 12.4 \%$ before and $122.7 \% \pm 17.2 \%$ after administration of bicuculline $(P<0.01)$. Furthermore, in the vehicle-pretreated rats, the degree

A

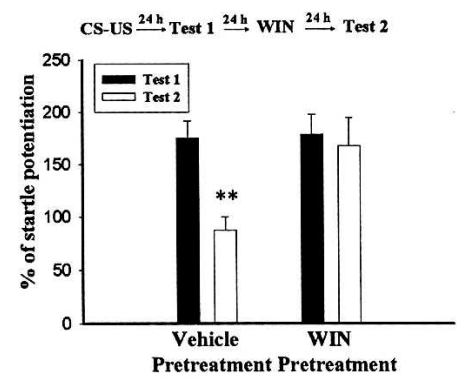

C

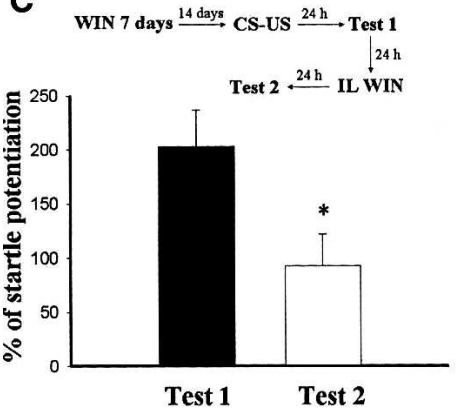

Figure 6. Tolerance to WIN-induced reduction of fear-potentiated startle after WIN pretreatment. $(A)$ Rats were pretreated with WIN (10 $\mathrm{mg} / \mathrm{kg}$, i.p.) for $7 \mathrm{~d}$ and were conditioned on day 8 . Retention of memory was tested $24 \mathrm{~h}$ later (Test 1 ). On day 10, the rats were infused with WIN $(1 \mu \mathrm{g}, n=7)$ or vehicle $(n=6)$ into the MPFC, and memory retention was assessed $24 \mathrm{~h}$ later (Test 2). (**) $P<0.01$ vs. Test $1 .(B)$ Cannula tip placements from rats infused with $(\bigcirc)$ vehicle or $(0)$ WIN in the experiments in $A$. (C) Recovery of extinction after withdrawal of WIN. Rats were injected with WIN $(10 \mathrm{mg} / \mathrm{kg}$, i.p.) for $7 \mathrm{~d}$. On day 22 (withdrawal $14 \mathrm{~d}$ ), the rats were given 10 light-foot shock pairings, and retention of memory was tested $24 \mathrm{~h}$ later (Test 1 ). On day 24, the rats were infused with WIN $(1 \mu \mathrm{g}, n=5)$ into the mPFC, and memory retention was assessed $24 \mathrm{~h}$ later (Test 2). (*) $P<0.05$ vs. Test $1 .(D)$ Cannula tip placements from rats infused with (O) WIN in the experiments in $C$. 
A

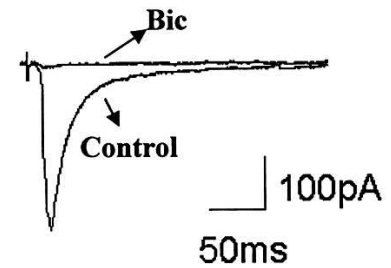

C

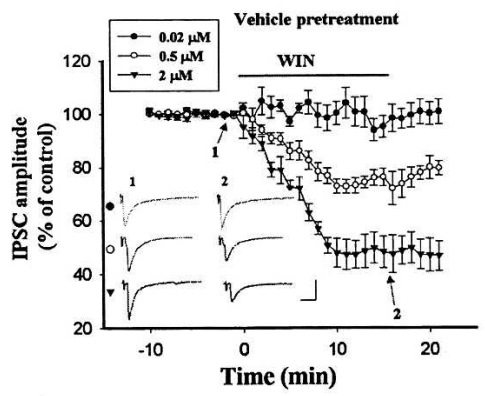

B

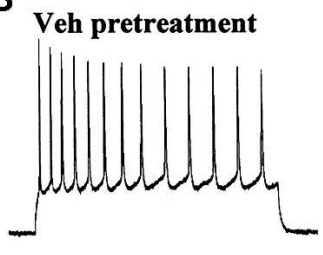

WIN pretreatment

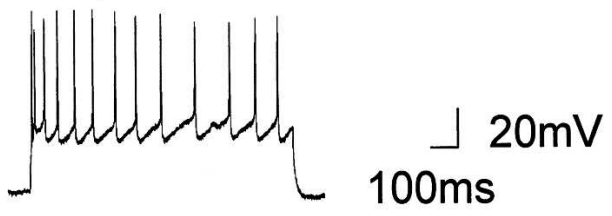

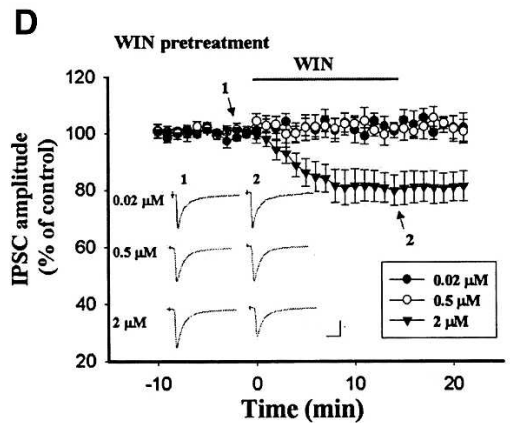

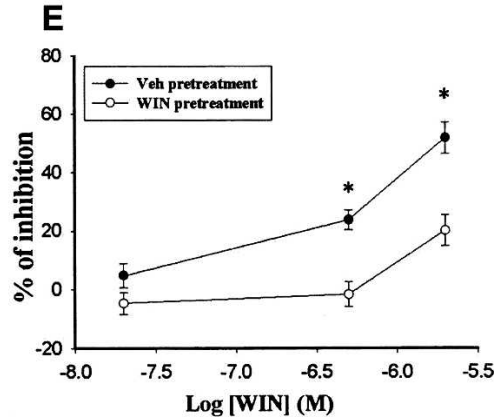

Figure 7. Tolerance to WIN-induced inhibition of IPSC in the mPFC slices. (A) IPSC recorded in the presence of CNQX $(10 \mu M)$ and D-APV $(50 \mu M)$ was completely blocked by bicuculline $(10 \mu \mathrm{M})$ confirming the mediation by $\mathrm{GABA}_{\mathrm{A}}$ receptors. (B) Representative traces showing the evoked spikes in response to 200-pA depolarizing current pulses in WIN- and Veh-pretreated rats. $(C, D)$ Application of different concentrations of WIN for 15 min reduced the amplitude of IPSC in slices from the (C) Veh-pretreated and $(D)$ WIN-pretreated rats. Calibration: $100 \mathrm{pA}, 25$ ms. (E) Significantly more inhibition of IPSC amplitude by WIN in Veh-pretreated rats than in WIN-pretreated rats. IC 20 shifted approximately from $0.3 \mu \mathrm{M}$ in Veh-pretreated rats to $1.9 \mu \mathrm{M}$ in WIN-pretreated rats.

of startle reduction after intra-IL infusion of bicuculline was not different from that of infusion of WIN $(P=0.29)$, suggesting the same mechanism exerted by WIN and bicuculline.

\section{Discussion}

Drug tolerance occurs when a subject's reaction to a drug decreases so that higher doses are required to achieve the same

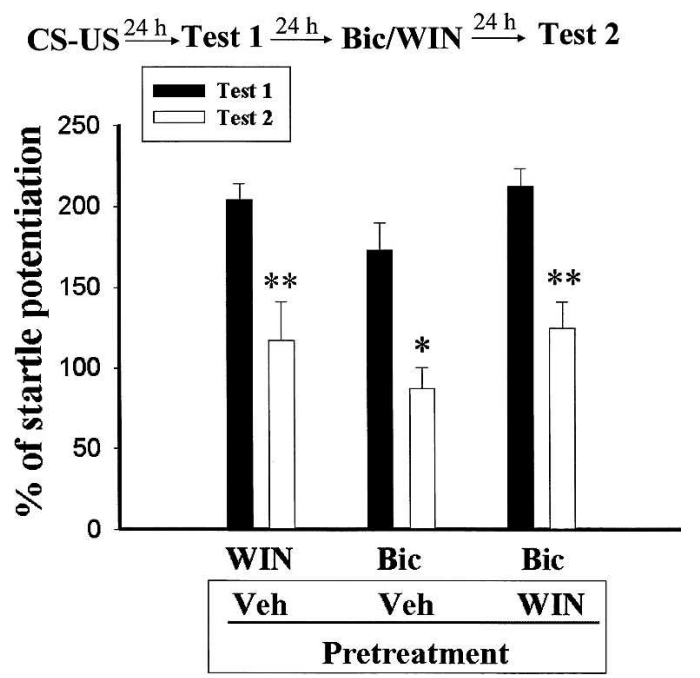

Figure 8. Intra-IL infusion of bicuculline decreases fear-potentiated startle. Rats were injected with WIN (10 mg/kg, i.p.) or vehicle once per day for $7 \mathrm{~d}$. On day 8 , the rats were given 10 light-foot shock pairings and retention of memory was tested $24 \mathrm{~h}$ later (Test 1 ). On day 10 , the rats were infused with bicuculline $(0.25 \mu \mathrm{g})$ to the IL in the vehicle-pretreated $(n=7)$ and WIN-pretreated $(n=6)$ rats, and memory retention was assessed $24 \mathrm{~h}$ later (Test 2). For comparison, WIN $(1 \mu \mathrm{g})$ was also infused to the IL in the vehicle-pretreated rats $(n=6) .\left(^{*}\right) P<0.05 ;\left(^{* *}\right) P<0.01$ vs. Test 1. effect. The cannabinoid receptors can adapt to maintain homeostasis, showing a high degree of plasticity that is tolerant to cannabinoid agonists after their prolonged exposure (Martin et al. 2004). Tolerance represents an excellent opportunity to explore the neural connection and mechanism involved in the physiological functions of the endocannabinoid system. Endocannabinoids are critically involved in the extinction of fear memory (Marsicano et al. 2002). Studies of extinction in animals and humans indicate that the mPFC is critically involved in this behavioral process (Morgan et al. 1993; Phelps et al. 2004; SotresBayon et al. 2004; Quirk et al. 2006). Recently, we have demonstrated that infusion of the $\mathrm{CB} 1$ receptor antagonist into the mPFC retarded extinction training-induced reduction of fearpotentiated startle. On the other hand, CB1 agonists mimicked extinction training, facilitating and causing a reduction of startle potentiation in a dose-dependent manner. The effect of CB1 agonists was mimicked by the endocannabinoid uptake inhibitor AM404 and the fatty acid amidehydrolase inhibitor URB597, and could be blocked by a specific CB1 receptor antagonist (Lin et al. 2008). In the present study, we show that WIN-pretreated rats exhibited much less extinction to cue-alone presentations. In addition, the reduction of fear-potentiated startle normally seen when CB1 receptor agonists were infused into the mPFC was absent in the WIN-pretreated rats. These results suggest that the endocannabinoid system within the mPFC plays an important role in the extinction of conditioned fear. It has been shown that cannabinoid receptors within the mPFC could modulate emotional memory through functional input from the amygdala (Laviolette and Grace 2006), supporting the notion that cannabinoid receptors within the IL and the integrity of mPFCamygdala-mPFC circuitry are important in the regulation of emotionally learned fear.

Endocannabinoid-mediated synaptic inhibition, as well as synaptic plasticity were reduced after long-term exposure to a cannabinoid agonist. In the synapses of nucleus accumbens, endocannabinoid-mediated long-term depression (LTD) was abol- 
ished after chronic treatment with cannabinoid (Hoffman et al. 2003; Mato et al. 2005). A complete block of LTD was detected even after a single injection of the active constituent of marijuana (Mato et al. 2004), suggesting that tolerance to cannabinoids developed rapidly. Anatomic evidence indicated that CB1 receptors were present on presynaptic GABAergic terminals within the mPFC (Bodor et al. 2005). Here we showed that chronic treatment with WIN resulted in decreased sensitivity of GABAergic synapses to the inhibitory effect of WIN. The correlation between decreased inhibition of GABAergic transmission and reduced inhibition of fear-potentiated startle after the development of tolerance supported the idea that endocannabinoid release after extinction training decreases GABAergic inhibition. Like hippocampus (Chagnac-Amitai and Connors 1989; Carlson et al. 2002; Chevaleyre and Castillo 2003), reduced GABAergic inhibition in the mPFC may result in neuronal synchronization, which, in turn, facilitated the induction of LTP. Subsequently, the increase in neural activity in the mPFC came to regulate the amygdala-mediated expression of conditioned fear (Rosenkranz and Grace 2001; Royer and Pare 2002; Quirk et al. 2003; Likhtik et al. 2005). Consistent with this notion, it has been shown that a potentiator of AMPA receptor facilitated extinction learning through activation of AMPA receptors mainly in the mPFC (Zushida et al. 2007), and bursting firing of ventromedial PFC neurons was necessary for the consolidation of extinction memory (Burgos-Robles et al. 2007).

Activation of $\mathrm{CB} 1$ receptors stimulates a pertussis toxinsensitive $G$ protein and inhibits adenylyl cyclase and PKA, leading to a decrease in constitutive phosphorylation of c-Raf at the inhibitory site (Ser259) and an increase in ERK phosphorylation (Davis et al. 2003). ERK is known to be required for several forms of synaptic plasticity and learning and memory (English and Sweatt 1997; Impey et al. 1998; Atkins et al. 1998; Coogan et al. 1999; Schafe and LeDoux 2000). In the mPFC, the phosphorylated level of ERK44 was significantly increased after extinction training (Cannich et al. 2004). Infusion of ERK inhibitor into the mPFC immediately after extinction training blocked extinction, suggesting the requirement of ERK activation in the behavioral process of extinction (Hugues et al. 2004). The inability of WIN to induce ERKs phosphorylation after development of cannabinoid tolerance further supports an essential role of endocannabinoids in fear extinction.

In summary, the present work shows for the first time that chronic administration of the synthetic cannabinoid agonist WIN produces a functional tolerance to the extinction of conditioned fear. Furthermore, this CB1 receptor tolerance appears to prevent WIN inhibition of GABAergic transmission and activation of ERKs in the mPFC. An elegant study by Marsicano et al. (2002) demonstrated that activation of CB1 receptor is essential for extinction, suggesting that endocannabinoids could be useful for the treatment of post-traumatic stress disorders. However, it should be cautioned that long-term marijuana use may limit its clinical efficacy. Overall, these findings give new insight into the cellular mechanism of fear extinction.

\section{Materials and Methods}

\section{Animals}

All procedures were approved by the Institutional Animal Care and Use Committee of the College of Medicine, National ChengKung University. Animals were housed in cages of four rats each in a temperature-controlled $\left(24^{\circ} \mathrm{C}\right)$ animal colony; pelleted rat chow and water were available ad libitum. They were maintained on a 12:12 light-dark cycle with lights on at $0700 \mathrm{~h}$. All behavioral procedures took place during the animal light cycle.

\section{Surgery}

Male Sprague-Dawley rats (175-200 g), anesthetized with sodium pentobarbital $(50 \mathrm{mg} / \mathrm{kg}$, i.p.), were mounted on a stereotaxic apparatus, and a cannula made of 22-gauge stainless steel tubing was implanted into the infralimbic cortex (IL). The coordinates were anteroposterior (AP) $+3.2 \mathrm{~mm}$, mediolateral (ML) $\pm 0.5 \mathrm{~mm}$, dorsoventral (DV) $-5.2 \mathrm{~mm}$ according to Paxinos and Watson (2004). Only rats with cannula tips within the boundaries of IL were included in the data analysis. Rats were monitored and handled daily and were given $7 \mathrm{~d}$ to recover. WIN55212-2 and AM251, D-APV and CNQX were obtained from Tocris Cooks Ltd. Drugs and vehicle solutions were administered in a volume of 0.8 $\mu \mathrm{L}$ at a rate of $0.1 \mu \mathrm{L} / \mathrm{min}$.

\section{Behavioral apparatus and procedures}

Rats were trained and tested in a stabilimeter device. A piezoelectric device mounted below the stabilimeter detects and transduces the motion of the cylinder produced by the whole body startle response of the rat (San Diego Instrument). The whole set-up was enclosed in a ventilated, sound-attenuating cabinet (length $38 \mathrm{~cm}$, width $38 \mathrm{~cm}$, and height $55 \mathrm{~cm}$ ). The acoustic startle stimulus was a 50-ms white noise at the intensity of $95 \mathrm{~dB}$. The visual CS was a 3.7-s light produced by an $8 \mathrm{~W}$ fluorescent bulb attached to the back of the stabilimeter. The US was a 0.6$\mathrm{mA}$ foot shock with duration of $0.5 \mathrm{~s}$. Rats were placed in the startle test boxes for $10 \mathrm{~min}$ and returned to their home cages on three consecutive days to habituate them to the test chamber and to minimize the effect of contextual conditioning.

\section{Experiment 1: Tolerance to antinociceptive effect after chronic WIN treatment}

Rats were treated with WIN (10 mg/kg, i.p.) or vehicle once per day for $7 \mathrm{~d}$. The $10 \mathrm{mg} / \mathrm{kg}$ dose of WIN was chosen because it has been shown to produce behavioral and functional tolerance to blockade of LTD by cannabinoids at synapses in the nucleus accumbens (Hoffman et al. 2003). Tolerance to the synaptic effect of cannabinoids developed in less than $7 \mathrm{~d}$ using a protocol identical to ours. In addition, our study revealed that the level of CB1 receptor in the IL synaptoneurosomes of the WIN-pretreated rats was significantly lower than those of naïve and vehicle-treated rats (Fig. 2). On day 8, all rats were injected with WIN $(10 \mathrm{mg} / \mathrm{kg}$, i.p.), and $20 \mathrm{~min}$ later, the antinociceptive effect was assessed using the tail-flick test. The tail-flick latency for each rat was determined three times, and the mean of these trials was designated as the baseline latency before drug injection. The intensity of the beam was adjusted to produce mean control reaction time between 1.5 and $4 \mathrm{~s}$. The cut-off time was fixed at $10 \mathrm{~s}$ in order to avoid any tissue damage. After determination of baseline latencies, rats received an intraperitoneal injection of WIN $(10 \mathrm{mg} / \mathrm{kg})$ or vehicle, and the reaction latencies were measured $20 \mathrm{~min}$ after injection.

\section{Experiment 2: Agonist-induced decrease in surface $\mathrm{CB1}$ receptor in the synaptoneurosome preparation}

Rats were pretreated chronically with WIN as described above. On day 8, brain slices containing IL were homogenized in $70 \mu \mathrm{L}$ of ice-cold lysis buffer in an Eppendorf tube. The buffer consisted of $118.5 \mathrm{mM} \mathrm{NaC1}, 4.7 \mathrm{mM} \mathrm{KC} 1,1.18 \mathrm{mM} \mathrm{MgSO}_{4}, 2.5 \mathrm{mM}$ $\mathrm{CaCl}_{2}, 1.18 \mathrm{mM} \mathrm{KH}_{2} \mathrm{PO}_{4}, 24.9 \mathrm{mM} \mathrm{NaHCO}, 10 \mathrm{mM}$ dextrose, 10 $\mu \mathrm{g} / \mathrm{mL}$ adenosine deaminase, with $\mathrm{pH}$ adjusted to 7.4 by bubbling with $95 \% \mathrm{O}_{2}+5 \% \mathrm{CO}_{2}$. Proteinase inhibitors $(0.01 \mathrm{mg} / \mathrm{mL}$ leupeptin, $0.005 \mathrm{mg} / \mathrm{mL}$ pepstatin $\mathrm{A}, 0.1 \mathrm{mg} / \mathrm{mL}$ aprotinin, and 5 $\mathrm{mM}$ Benzamide) were included in the buffer to minimize proteolysis. The homogenate was diluted with $350 \mu \mathrm{L}$ of additional ice-cold lysis buffer. This mixture was loaded into a l-mL tuberculin syringe attached to a $13-\mathrm{mm}$ diameter Millipore syringe filter holder. The diluted filtrate was forced over three layers of nylon (Tetko; 100- $\mu \mathrm{m}$ pores) pre-wetted with $150 \mu \mathrm{L}$ of lysis 
buffer, and collected in a 1.5-mL Eppendorf tube. The nylonprefiltered mixture was loaded into another 1-mL tuberculin syringe and forced through a pre-wetted $5 \mu \mathrm{m}$ Millipore nitrocellulose filter. The homogenate was kept ice cold at all times to minimize proteolysis. The filtered particulate was then spun at $1000 \mathrm{~g}$ for $15 \mathrm{~min}$ at $4^{\circ} \mathrm{C}$. The supernatant was removed, and the pellet (synaptoneurosome) was re-suspended in $80 \mu \mathrm{L}$ of lysis buffer. CB1 receptor was quantified by Western blot analysis with rabbit anti-CB1 receptor antibody (N-terminus, Upstate Biotech Inc.).

\section{Experiment 3: Tolerance to WIN-induced ERKs phosphorylation}

Rats were injected intraperitoneally with WIN or vehicle for $7 \mathrm{~d}$. On day 8 , the rats were decapitated and minislices containing mPFC were made. One hour later, slices were incubated with WIN $(2 \mu \mathrm{M})$ for $15 \mathrm{~min}$ and ERK phosphorylation was analyzed with antibody directly against the active form of ERKs. The tissues were sonicated briefly in ice-cold buffer $(50 \mathrm{mM}$ Tris- $\mathrm{HCl}$, $\mathrm{pH} 7.5,0.3 \mathrm{M}$ sucrose, $5 \mathrm{mM}$ EDTA, $2 \mathrm{mM}$ sodium pyrophosphate, $1 \mathrm{mM}$ sodium orthovanadate, $1 \mathrm{mM}$ phenylmethylsulfonyl fluoride [PMSF], $20 \mu \mathrm{g} / \mathrm{mL}$ leupeptin, $4 \mu \mathrm{g} / \mathrm{mL}$ aprotinin, and $1 \%$ Triton X-100). Following sonication, the samples were centrifuged at $18,200 \mathrm{~g}$ for $30 \mathrm{~min}$, and the supernatant was obtained. Protein concentration in the soluble fraction was then measured using a Bradford assay, with bovine serum albumin as the standard. Equivalent amounts of protein for each sample were resolved in $8.5 \%$ SDS-polyacrylamide gels, blotted electrophoretically to polyvinylidene difluoride (PVDF) membrane (Millipore), and blocked overnight in TBS buffer $(50 \mathrm{mM}$ Tris$\mathrm{HCl}, \mathrm{pH} 7.5,150 \mathrm{mM} \mathrm{NaCl}$ ) containing $2 \%$ bovine serum albumin. For detection of the phosphorylated forms of ERK, blots were incubated with anti-phospho-ERK (1:1000; Cell Signaling Technology) antibody. To control the content of the specific protein per lane, membranes were stripped with $100 \mathrm{mM} \beta$ mercaptoethanol and $2 \%$ SDS in $62.5 \mathrm{mM}$ Tris- $\mathrm{HCl}, \mathrm{pH} 6.8$, for $30 \mathrm{~min}$ at $70^{\circ} \mathrm{C}$ and re-probed with rabbit anti-pan-ERK (Cell Signaling Tech.) antibody. The membranes were washed with TBS-T buffer $(50 \mathrm{mM}$ Tris- $\mathrm{HCl}, \mathrm{pH} 7.5,150 \mathrm{mM} \mathrm{NaCl}, 0.05 \%$ Tween 20) four times, and then were incubated with chemiluminescent substrate, ECL plus (Amersham Biosciences) for $3 \mathrm{~min}$. Chemiluminescent signals were visualized by exposing the membrane to KODAK BioMax light films, and the entire film was digitized by a Gel Doc video camera. Band intensities (optical density units, $\mathrm{OD} / \mathrm{mm}^{2}$ ) were quantified densitometrically using the Quantity One software (Bio-Rad). Western blots were developed in the linear range used for densitometry. The levels of pERK in the WIN-pretreated rats were normalized to total kinase levels and then were expressed as a percentage of that in the vehicle controls.

\section{Experiment 4: Resistance to the extinction}

Rats were treated with WIN (10 mg/kg, i.p.) or vehicle once per day for $7 \mathrm{~d}$. On day 8 , all rats were placed in the startle boxes and received 10 light-foot shock pairings with an ITI of $2 \mathrm{~min}$. On day 9 , the rats were tested for fear-potentiated startle (Test 1 ). The test involved 30 startle-eliciting noise bursts presented alone (noise-alone trial) and 30 noise bursts presented $3.2 \mathrm{~s}$ after onset of the 3.7-s light (light-noise trials). The two trial types were presented in a balanced mixed order (ITI, $30 \mathrm{~s}$ ). The percentage of fear-potentiated startle was computed as follows:

$$
\frac{\text { (startle amplitude on CS-noise }- \text { noise-alone trials) }}{\text { (noise-alone trials) }} \times 100 \text {. }
$$

On day 10 , the rats were returned to the startle box and were given three sessions of 10 presentations of the 3.7-s light in the absence of either shock or the startle-elicited noise burst (lightalone trials). Each session was separated by 10 min with an ITI of $1 \mathrm{~min}$. The retention of memory was tested the next day (Test 2).
Experiment 5: Resistance to the facilitation of extinction

Rats were treated chronically with WIN as in the above experiments. On day 8 , the rats were submitted to a standard fear conditioning procedure, and fear-potentiated startle was measured $24 \mathrm{~h}$ later (Test 1 ). On day 10, they were infused with WIN into the IL 30 min before light-alone trials (one block of 10 presentations of light-alone trials). We used a 10-trials protocol instead of 30 trials because it is easier to detect the effect of drugs on extinction. WIN $(0.05 \mu \mathrm{g})$ was infused into the IL $30 \mathrm{~min}$ before CS-alone trials. A separate group of rats that received WIN infusion but no extinction training served as No-CS control. The rats were tested for fear-potentiated startle $24 \mathrm{~h}$ after extinction training (day 4, Test 2).

\section{Experiment 6: Resistance to WIN-induced reduction of fear-potentiated startle}

WIN-pretreated rats were conditioned on day 8 , and memory retention was assessed $24 \mathrm{~h}$ later (Test 1 ). On the next day, all rats received intra-IL infusion of WIN $(1 \mu \mathrm{g})$, and the percentage of fear-potentiated startle was measured $24 \mathrm{~h}$ later (Test 2).

\section{Experiment 7: Tolerance to WIN-induced inhibition of GABAergic neurotransmission}

Rats were injected intraperitoneally with WIN or vehicle for $7 \mathrm{~d}$. On day 8 , the rats were decapitated, and their were brains rapidly removed and placed in cold oxygenated artificial cerebrospinal fluid (ACSF) solution. Subsequently, the brain was hemisected and transverse slices of $250 \mu \mathrm{m}$ thickness were cut, and the appropriate slices were placed in a beaker of oxygenated ACSF for at least $1 \mathrm{~h}$ at room temperature before recording. ACSF solution had the following composition: $117 \mathrm{mM} \mathrm{NaCl}, 4.7 \mathrm{mM} \mathrm{KCl}, 2.5$ $\mathrm{mM} \mathrm{CaCl}, 1.2 \mathrm{mM} \mathrm{MgCl}_{2}, 25 \mathrm{mM} \mathrm{NaHCO}_{3}, 1.2 \mathrm{mM} \mathrm{NaH}_{2} \mathrm{PO}_{4}$, and $11 \mathrm{mM}$ glucose. The ACSF was bubbled continuously with $95 \% \mathrm{O}_{2}-5 \% \mathrm{CO}_{2}$ and had the $\mathrm{pH}$ of 7.4 .

A single slice was transferred to the recording chamber, in which it was held submerged and maintained at $32^{\circ} \pm 1^{\circ} \mathrm{C}$. The chamber consisted of a circular well of a low volume (1-2 mL) and was perfused constantly at a rate of $2-3 \mathrm{~mL} / \mathrm{min}$. Whole-cell patch-clamp recordings were made from the mPFC neurons. Neurons were visualized with infrared video microscope using a $40 \times$ water immersion objective on an upright microscope (UTV1X Olympus). Synaptic potentials were recorded by placing a stimulation electrode on the layer II and the recording electrode on the layer $\mathrm{V}$ of the infralimbic (IL) subregion, which projects to subcortical structures including the amygdala (Gabbott et al. 2005). Electrical stimuli ( $150 \mu$ s in duration) were delivered at a frequency of $0.05 \mathrm{~Hz}$. Patch electrodes were pulled from a thickwall glass capillary $(0.75 \mathrm{~mm}$ I.D., $1.5 \mathrm{~mm}$ O.D.) to a tip resistance of 3-5 $\mathrm{M} \Omega$. The internal solution contained $115 \mathrm{mM} \mathrm{KCl}$, $5 \mathrm{mM} \mathrm{NaCl}, 1 \mathrm{mM}$ EGTA, $0.3 \mathrm{mM} \mathrm{CaCl}_{2}, 2 \mathrm{mM} \mathrm{MgCl} 2,5 \mathrm{mM}$ Na-ATP, $0.4 \mathrm{mM}$ Na-GTP, $10 \mathrm{mM}$ HEPES. The final $\mathrm{pH}$ of the internal solution was adjusted to 7.2 by adding $1 \mathrm{M} \mathrm{KOH}$; the final osmolarity was adjusted to 280 mOsm by adding sucrose. Records were low-pass-filtered at $5 \mathrm{kHz}$ and digitized at $10 \mathrm{kHz}$. The signal was monitored and recorded with an Axopatch 200B amplifier. On-line analysis and control of experimental acquisition were accomplished via a 586 (Intel)-based PC clone and a Digidata 1320 computer interface. The mPFC pyramidal neurons were injected with a depolarizing current $(1000 \mathrm{~ms}, 200 \mathrm{pA})$ to elicit action potential discharges. $\mathrm{GABA}_{\mathrm{A}}$-mediated IPSC was evoked when the neurons were voltage-clamped at $-70 \mathrm{mV}$. To isolate IPSC, 6-cyano-7-nitroquinoxaline-2,3-dione (CNQX, 10 $\mu \mathrm{M})$ and D-2-amino-5-phosphonovalerate (D-APV, $50 \mu \mathrm{M})$ were present in the perfusion solution. The membrane input resistance $\left(R_{\mathrm{m}}\right)$ was measured from 10-mV, 200-ms depolarizing and hyperpolarizing pulses in voltage-clamp mode at a holding potential of $-70 \mathrm{mV}$. 


\section{Experiment 8: Infusion of bicuculline to the IL}

WIN-pretreated rats were conditioned on day 8 , and memory retention was assessed $24 \mathrm{~h}$ later (Test 1 ). On the next day, all rats received intra-IL infusion of bicuculline $(0.25 \mu \mathrm{g})$, and the percentage of fear-potentiated startle was measured $24 \mathrm{~h}$ later (Test 2).

\section{Data analysis}

Two-way analysis of variance (ANOVA) was used to analyze the effects of group (vehicle vs. WIN pretreatment) and drug treatment (WIN vs. vehicle) on the antinociception and startle reduction of WIN followed by Bonferroni post-tests. All values are presented as mean \pm standard error of the mean. Levels of $P<0.05$ were considered to be of statistical significance.

\section{Acknowledgments}

This study was supported by grants NSC94-2752-B-006-001-PAE from the National Science Council, N08I97N from the National Health Research Institute, and Landmark Project (A0031) of the National Cheng-Kung University of Taiwan. We thank Min-Der Lai and Chun-Lin Su for critical comments on the manuscript.

\section{References}

Atkins, C.M., Selcher, J.C., Petraitis, J.J., Trzaskos, J.M., and Sweatt, J.D. 1998. The MAPK cascade is required for mammalian associative learning. Nat. Neurosci. 1: 602-609.

Barad, M., Gean, P.W., and Lutz, B. 2006. The role of the amygdala in the extinction of conditioned fear. Biol. Psychiatry 60: 322-328.

Berman, D.E. and Dudai, Y. 2001. Memory extinction, learning anew, and learning the new: Dissociations in the molecular machinery of learning in cortex. Science 291: 2417-2419.

Bodor, A.L., Katona, I., Nyiri, G., Mackie, K., Ledent, C., Hajos, N., and Freund, T.F. 2005. Endocannabinoid signaling in rat somatosensory cortex: Laminar differences and involvement of specific interneuron types. J. Neurosci. 25: 6845-6856.

Bouton, M.E. 2002. Context, ambiguity, and unlearning: Sources of relapse after behavioral extinction. Biol. Psychiatry 52: 976-986.

Burgos-Robles, A., Vidal-Gonzalez, I., Santini, E., and Quirk, G.J. 2007. Consolidation of fear extinction requires NMDA receptor-dependent bursting in the ventromedial prefrontal cortex. Neuron 53: 871-880.

Cannich, A., Wotjak, C.T., Kamprath, K., Hermann, H., Lutz, B., and Marsicano, G. 2004. CB1 cannabinoid receptors modulate kinase and phosphatase activity during extinction of conditioned fear in mice. Learn. Mem. 11: 625-632.

Carlson, G., Wang, Y., and Alger, B.E. 2002. Endocannabinoids facilitate the induction of LTP in the hippocampus. Nat. Neurosci. 5: 723-724.

Chagnac-Amitai, Y. and Connors, B.W. 1989. Horizontal spread of synchronized activity in neocortex and its control by GABA-mediated inhibition. J. Neurophysiol. 61: 747-758.

Chevaleyre, V. and Castillo, P.E. 2003. Heterosynaptic LTD of hippocampal GABAergic synapses: A novel role of endocannabinoids in regulating excitability. Neuron 38: 461-472.

Chhatwal, J.P., Davis, M., Maguschak, K.A., and Ressler, K.J. 2005. Enhancing cannabinoid neurotransmission augments the extinction of conditioned fear. Neuropsychopharmacology 30: 516-524.

Coogan, A.N., O'Leary, D.M., and O'Connor, J.J. 1999. P42/44 MAP kinase inhibitor PD98059 attenuates multiple forms of synaptic plasticity in rat dentate gyrus in vitro. J. Neurophysiol. 81: 103-110.

Coutts, A.A., Anavi-Goffer, S., Ross, R.A., MacEwan, D.J., Mackie, K., Pertwee, R.G., and Irving, A.J. 2001. Agonist-induced internalization and trafficking of cannabinoid CB1 receptors in hippocampal neurons. J. Neurosci. 21: 2425-2433.

Davis, M. 2000. The role of the amygdala in conditioned and unconditioned fear and anxiety. In The amygdala: A functional analysis (ed. J.P. Aggleton), pp. 213-287. Oxford University Press, New York.

Davis, M.I., Rones, J., and Lovinger, D.M. 2003. A predominant role for inhibition of the adenylyl cyclase/protein kinase A pathway in ERK activation by cannabinoid receptor 1 in N1E-115 neuroblastoma cells. J. Biol. Chem. 278: 48973-48980.

English, J.D. and Sweatt, J.D. 1997. A requirement for the mitogen-activated protein kinase cascade in hippocampal long-term potentiation. J. Biol. Chem. 272: 19103-19106.

Falls, W.A., Miserendino, M.J., and Davis, M. 1992. Extinction of fear-potentiated startle: Blockade by infusion of an NMDA antagonist into the amygdala. J. Neurosci. 12: 854-863.
Gabbott, P.L., Warner, T.A., Lays, P.R., Salway, P., and Busby, S.J. 2005. Prefrontal cortex in the rat: Projections to subcortical autonomic, motor, and limbic centers. J. Comp. Neurol. 492: 145-177.

Hoffman, A.F., Oz, M., Caulder, T., and Lupica, C.R. 2003. Functional tolerance and blockade of long-term depression at synapses in the nucleus accumbens after chronic cannabinoid exposure. J. Neurosci. 23: $4815-4820$

Hsieh, C., Brown, S., Derleth, C., and Mackie, K. 1999. Internalization and recycling of the CB1 cannabinoid receptor. J. Neurochem. 73: 493-501.

Huang, Y.Y., Simpson, E., Kellendonk, C., and Kandel, E.R. 2004. Genetic evidence for the bidirectional modulation of synaptic plasticity in the prefrontal cortex by D1 receptors. Proc. Natl. Acad. Sci. 101: 3236-3241.

Hugues, S., Deschaux, O., and Garcia, R. 2004. Postextinction infusion of a mitogen-activated protein kinase inhibitor into the medial prefrontal cortex impairs memory of the extinction of conditioned fear. Learn. Mem. 11: 540-543.

Impey, S., Smith, D.M., Obrientan, K., Donahue, R., Wade, C., and Storm, D.R. 1998. Stimulation of cAMP response element (CRE)-mediated transcription during contextual learning. Nat. Neurosci. 1: 595-601.

Iversen, L. 2003. Cannabis and the brain. Brain 126: 1252-1270.

Laviolette, S.R. and Grace, A.A. 2006. Cannabinoids potentiate emotional learning plasticity in neurons of the medial prefrontal cortex through basolateral amygdala inputs. J. Neurosci. 26: 6458-6468.

LeDoux, J.E. 2000. Emotion circuits in the brain. Annu. Rev. Neurosci. 23: $155-184$.

Likhtik, E., Pelletier, J.G., Paz, R., and Pare, D. 2005. Prefrontal control of the amygdala. J. Neurosci. 25: 7429-7437.

Lin, H.C., Mao, S.C., Su, C.L., and Gean, P.W. 2008. The role of prefrontal cortex CB1 receptors in the modulation of fear memory. Cereb. Cortex. doi: 10.1093/cercor/bhn075.

Maldonado, R. 2002. Study of cannabinoid dependence in animals. Pharmacol. Ther. 95: 153-164.

Maren, S. and Quirk, G.J. 2004. Neuronal signaling of fear memory. Nat. Rev. Neurosci. 5: 844-852.

Marsicano, G., Wotjak, C.T., Azad, S.C., Bisogno, T., Rammes, G., Cascio, M.G., Hermann, H., Tang, J., Hofmann, C., Zieglgansberger, W., et al. 2002. The endogenous cannabinoid system controls extinction of aversive memories. Nature 418: 530-534.

Martin, B.R., Sim-Selley, L.J., and Selley, D.E. 2004. Signaling pathways involved in the development of cannabinoid tolerance. Trends Pharmacol. Sci. 25: 325-330.

Mato, S., Chevaleyre, V., Robbe, D., Pazos, A., Castillo, P.E., and Manzoni, O.J. 2004. A single in-vivo exposure to $\Delta_{9}$ THC blocks endocannabinoid-mediated synaptic plasticity. Nat. Neurosci. 7: 585-586.

Mato, S., Robbe, D., Puente, N., Grandes, P., and Manzoni, O.J. 2005. Presynaptic homeostatic plasticity rescues long-term depression after chronic $\Delta^{9}$-tetrahydrocannabinol exposure. J. Neurosci. 25: 11619-11627.

Morgan, M.A., Romanski, L.M., and LeDoux, J.E. 1993. Extinction of emotional learning: Contribution of medial prefrontal cortex. Neurosci. Lett. 163: 109-113.

Myers, K.M. and Davis, M. 2002. Behavioral and neural analysis of extinction. Neuron 36: 567-584.

Pavlov, I.P. 1927. Conditioned reflex. Oxford, London, UK.

Paxinos, G. and Watson, G. 2004. The rat brain in stereotaxic coordinates: The new coronal set-161 diagrams. Academic Press, New York.

Phelps, E.A., Delgado, M.R., Nearing, K.I., and LeDoux, J.E. 2004. Extinction learning in humans: Role of the amygdala and vmPFC. Neuron 43: 897-905.

Quirk, G.J., Likhtik, E., Pelletier, J.G., and Pare, D. 2003. Stimulation of medial prefrontal cortex decreases the responsiveness of central amygdala output neurons. J. Neurosci. 23: 8800-8807.

Quirk, G.J., Garcia, R., and Gonzalez-Lima, F. 2006. Prefrontal mechanisms in extinction of conditioned fear. Biol. Psychiatry 60: 337-343.

Rescorla, R.A. 2001. Experimental extinction. In Handbook of contemporary learning theories (eds. R.R. Mowrer and S. Klein), pp. 119-154. Erlbaum, Mahwah, NJ.

Rosenkranz, J.A. and Grace, A.A. 2001. Dopamine attenuates prefrontal cortical suppression of sensory inputs to the basolateral amygdala of rats. J. Neurosci. 21: 4090-4103.

Royer, S. and Pare, D. 2002. Bidirectional synaptic plasticity in intercalated amygdala neurons and the extinction of conditioned fear responses. Neuroscience 115: 455-462.

Rubino, T., Guidali, C., Vigano, D., Realini, N., Valenti, M., Massi, P., and Parolaro, D. 2008. CB1 receptor stimulation in specific brain areas differently modulate anxiety-related behaviour.

Neuropharmacology 54: 151-160. 
Schafe, G.E. and LeDoux, J.E. 2000. Memory consolidation of auditory Pavlovian fear conditioning requires protein synthesis and protein kinase A in the amygdala. J. Neurosci. 20: RC96-1-RC96-5.

Sotres-Bayon, F., Bush, D.E., and LeDoux, J.E. 2004. Emotional preservation: An update on prefrontal-amygdala interactions in fear extinction. Learn. Mem. 11: 525-535.

Tournier, M., Sorbara, F., Gindre, C., Swendsen, J.D., and Verdoux, H. 2003. Cannabis use and anxiety in daily life: A naturalistic investigation in a non-clinical population. Psychiatry Res. 118: 1-8. Viveros, M.P., Llorente, R., Moreno, E., and Marco, E.M. 2005.
Behavioural and neuroendocrine effects of cannabinoids in critical developmental periods. Behav. Pharmacol. 16: 353-362.

Zushida, K., Sakurai, M., Wada, K., and Sekiguchi, M. 2007. Facilitation of extinction learning for contextual fear memory by PEPA: A potentiator of AMPA receptors. J. Neurosci. 27: 158-166.

Received May 25, 2008; accepted in revised form September 21, 2008. 


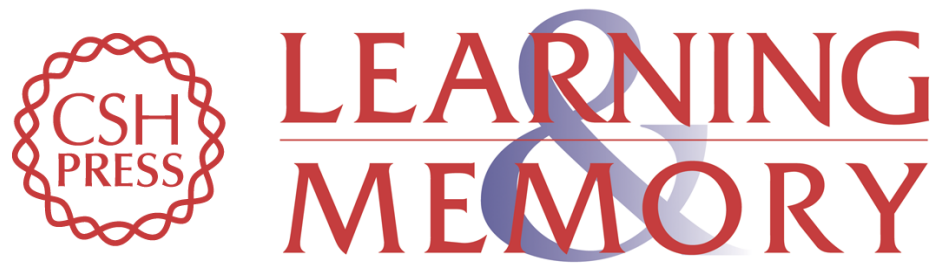

\section{Chronic cannabinoid administration in vivo compromises extinction of fear memory}

Hui-Ching Lin, Sheng-Chun Mao, Po-See Chen, et al.

Learn. Mem. 2008, 15:

Access the most recent version at doi:10.1101//m.1081908

References This article cites 46 articles, 17 of which can be accessed free at: http://learnmem.cshlp.org/content/15/12/876.full.html\#ref-list-1

License

Email Alerting Receive free email alerts when new articles cite this article - sign up in the box at the Service top right corner of the article or click here. 